05,12

\title{
Магнитные и резонансные свойства наночастиц ферригидрита, легированных кобальтом
}

\author{
() С.В. Столяр ${ }^{1,2}$, Р.Н. Ярославцев ${ }^{1}$, Р.С. Исхаков ${ }^{2}$, О.А. Баюков ${ }^{2}$, Д.А. Балаев ${ }^{1,2}$, \\ А.А. Дубровскийㄹ, А.А. Красиков ${ }^{2}$, В.П. Ладыгина ${ }^{3}$, А.М. Воротынов ${ }^{2}$, М.Н. Волочаев ${ }^{2}$ \\ ${ }^{1}$ Сибирский фредеральный университет, \\ Красноярск, Россия \\ ${ }^{2}$ Институт физики им. Л.В. Киренского СО РАН, \\ Красноярск, Россия \\ ${ }^{3}$ Международный научный центр исследований экстремальных состояний организма \\ при Президиуме КНЦ СО РАН, \\ Красноярск, Россия \\ E-mail: stol@iph.krasn.ru
}

(Поступила в Редакцию 10 августа 2016 г.)

Методом гидролиза солей $3 d$-металлов получены порошки наночастиц ферригидрита и наночастиц ферригидрита, легированных кобальтом в соотношении 5:1. Методом мессбауэровской спектроскопии показано, что кобальт равномерно размещается по характерным кристаллохимическим позициям ионов железа. Определены температуры блокировки. Оценены размеры частиц, величины намагниченности, константы поверхностной и объемной анизотропии. Легирование кобальтом приводит к существенному увеличению константы анизотропии частицы и формирует поверхностную вращательную анизотропию с $K_{u}=1.6 \cdot 10^{-3} \mathrm{erg} / \mathrm{cm}^{2}$.

Работа поддержана Специальной программой Министерства образования и науки РФ для Сибирского федерального университета, а также грантами РФФИ № 16-03-00969 и РФФИ-ККФН р-сибирь-а (проект № 15-42-04171).

DOI: $10.21883 /$ FTT.2017.03.44166.329

\section{1. Введение}

В настоящее время огромное внимание уделяется дисперсным магнитным наночастицам на основе железа [1]. Среди оксигидроксидов железа наибольшего внимания заслуживает метастабильный ферригидрит, свойства которого определяются составом, структурой и способом получения [2]. Химическую формулу ферригидрита обычно записывают в следующем виде: $5 \mathrm{Fe}_{2} \mathrm{O}_{3} \cdot 9 \mathrm{H}_{2} \mathrm{O}$, однако ввиду дефектности структуры количество ОН-связей может меняться. В ферригидрите присутствует два типа анионных упаковок [3]. При образовании фрагмента с кубической упаковкой, в котором анионные плоскости располагаются в последовательности $A B C A B C$, ионы $\mathrm{Fe}^{3+}$ заселяют октаэдрические позиции, формируя два соседних слоя октаэдров, занятых железом. При образовании фрагмента с гексагональной упаковкой, в котором анионные плоскости располагаются в последовательности $A B A B(A C A C)$, формируются одиночные слои октаэдров [4]. Ферригидрит формируется в ядре белкового комплекса ферритина, представляющего собой капсулу из белка апоферритина (наружный и внутренний диаметры - 12 и 5-8 nm соответственно) [5]. Этот комплекс присутствует в органах практически всех высших животных и выполняет функцию хранения („депо“) железа.
Массивный ферригидрит является антиферромагнетиком (AF). Однако при уменьшении размера AF-частиц до наномасштаба магнитные свойства материала кардинально меняются. Во-первых, происходит рост антиферромагнитной восприимчивости и изменяется ее температурная зависимость [6,7]. Во-вторых, снижаются поле спин-флоп перехода и температура Нееля частицы $[8,9]$. В-третьих (и это качественно новый эффект), наночастицы ферригидрита приобретают постоянный магнитный момент, обусловленный неполной компенсацией моментов подрешеток в столь малых объектах. В результате, каждая наночастица ферригидрита оказывается в магнитном отношении необычным „гибридом“ антиферромагнетика и феррита. Благодаря необычным свойствам, приобретаемым при переходе в состояние нанодисперсии, частицы ферригидрита могут составить конкуренцию наночастицам обычных ферро- и ферримагнетиков, используемых в различных практических приложениях [10], в том числе для целенаправленного переноса лекарственных препаратов в организме, а также для контрастирования в магниторезонансной томографии [11]. Расширить область применения наночастиц можно путем модификации их магнитных свойств в результате легирования [12]. В настоящей работе изучены модификации статических и динамических магнитных свойств наночастиц ферригидрита, полученных химическим способом и легированных кобальтом. 


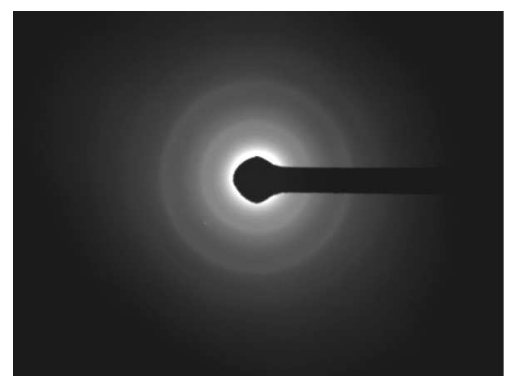

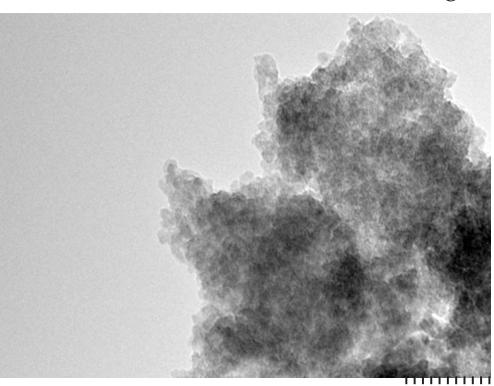

$20 \mathrm{~nm}$

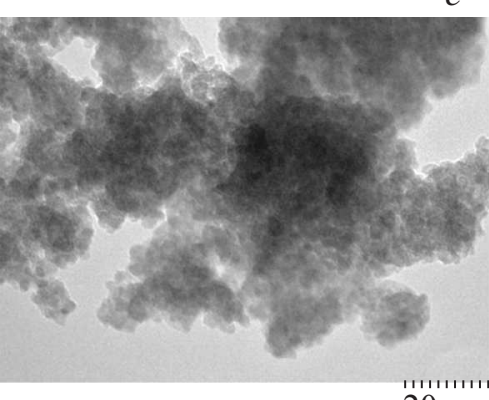

Рис. 1. Микродифракция наночастиц ферригидрита $(a)$, изображения просвечивающего электронного микроскопа для нелегированных $(b)$ и легированных кобальтом наночастиц ферригидрита $(c)$.

\section{2. Эксперимент}

Химический ферригидрит получался медленным добавлением раствора щелочи $\mathrm{NaOH}(1 \mathrm{M})$ при комнатной температуре с постоянным перемешиванием к раствору хлорида железа $\mathrm{FeCl}_{3}(0.02 \mathrm{M})$ до достижения нейтрального значения $\mathrm{pH}$. Скорость добавления щелочи варьировалась в диапазоне от 0.01 до 0.001 $\mathrm{mol} / \mathrm{min}$. Аналогичным образом получался образец, легированный кобальтом, но с добавлением в реакционный раствор соли кобальта (III). Выпавший осадок собирался на фильтре. Полученный осадок промывался и высушивался при комнатной температуре. Электронномикроскопические исследования проводились на просвечивающем электронном микроскопе Hitachi HT7700 (ускоряющее напряжение $100 \mathrm{kV}$ ) Центра коллективного пользования Красноярского научного центра СО РАН. Мессбауэровские спектры были измерены на спектрометре $\mathrm{MC}-1104 \mathrm{Em}$ с источником ${ }^{57} \mathrm{Co}(\mathrm{Cr})$ на порошковых образцах толщиной $5-10 \mathrm{mg} / \mathrm{cm}^{2}$ по естественному содержанию железа. Низкотемпературные измерения проведены с использованием криостата фирмы ООО „КРИОТРЕЙД““. Изомерные химические сдвиги указаны относительно $\alpha$-Fe. Магнитные измерения проводились на вибрационном магнитометре [13]. Исследуемый порошок фиксировался в измерительной капсуле в парафине. Для измерений температурных зависимостей магнитного момента $M(T)$ использовались режимы охлаждения без поля (ZFC - zero field cooling) и во внешнем поле (FC - field cooling). Спектры магнитного резонанса были получены на спектрометре Bruker ELEXSYS 560, работающем в $X$-диапазоне (характерная частота СВЧ-излучения $\sim 9.4 \mathrm{GHz}$ ), в области температур $100-300 \mathrm{~K}$.

\section{3. Результаты и обсуждение}

3.1. Результаты электронной микроскоп и и. На рис. 1 представлены результаты просвечивающей электронной микроскопии полученных наночастиц. На рис. 1, $a$ приведена картина микродифракции, кото- рая является характерной для наночастиц ферригидрита $[14,15]$. Наблюдаются два диффузных отражения с межплоскостными расстояниями $d_{1}=1.6 \AA, d_{2}=2.7 \AA$. Средний размер частиц составил $\sim 25 \AA$ (рис. $1, b$ ). Легирование кобальтом приводит к увеличению размеров до $35 \AA$ (рис. $1, c)$. В табл. 1, в частности, приведены результаты рентгенофлуоресцентного анализа наночастиц, легированных кобальтом. Согласно полученным результатам, соотношение атомных концентраций $\mathrm{Fe}: \mathrm{Co}$ составляет 5:1. Картины микродифракции наночастиц, легированных кобальтом, оказались идентичными представленной на рис. $1, a$.

3.2. Результаты мессбауэровской спектроскопи и. На рис. 2 приведен мессбауэровский спектр синтезированных наночастиц, измеренный при температуре $4 \mathrm{~K}$, представляющий собой зеемановский секстет.

Таблица 1. Элементный состав наночастиц ферригидрита

\begin{tabular}{c|c|c|c|c}
\hline \multirow{2}{*}{ Элемент } & \multicolumn{2}{|c|}{$\begin{array}{c}\text { Ферригидрит, } \\
\text { полученный химически }\end{array}$} & \multicolumn{2}{c}{$\begin{array}{c}\text { Ферригидрит, } \\
\text { легированный Сo }\end{array}$} \\
\cline { 2 - 5 } & wt.\% & at.\% & wt.\% & at.\% \\
\hline \multirow{2}{*}{ Fe } & 66.97 & 36.73 & 55.12 & 30.32 \\
O & 33.03 & 63.26 & 33.09 & 63.53 \\
Co & - & - & 11.79 & 6.15
\end{tabular}

Таблица 2. Мессбауэровские параметры

\begin{tabular}{c|c|c|c|c|c}
\hline $\mathrm{IS}, \mathrm{mm} / \mathrm{s}$ & $H, \mathrm{kOe}$ & $\mathrm{QS}, \mathrm{mm} / \mathrm{s}$ & $W, \mathrm{~mm} / \mathrm{s}$ & $A$ & Позиция \\
\hline 0.409 & 521 & 0 & 0.22 & 0.038 & - \\
0.639 & 516 & 0 & 0.29 & 0.070 & - \\
0.431 & 511 & 0 & 0.35 & 0.10 & - \\
0.492 & 491 & -0.03 & 0.56 & 0.473 & $\mathrm{Fe} 1$ \\
0.453 & 467 & 0 & 0.55 & 0.239 & $\mathrm{Fe} 2$ \\
0.464 & 436 & -0.01 & 0.56 & 0.080 & -
\end{tabular}

Примечание. IS - изомерный химический сдвиг относительно $\alpha$-Fe, $H$ - сверхтонкое поле, QS - квадрупольное расщепление, $W-$ ширина линии поглощения, $A-$ площадь под парциальным дублетом (заселенность позиции). 


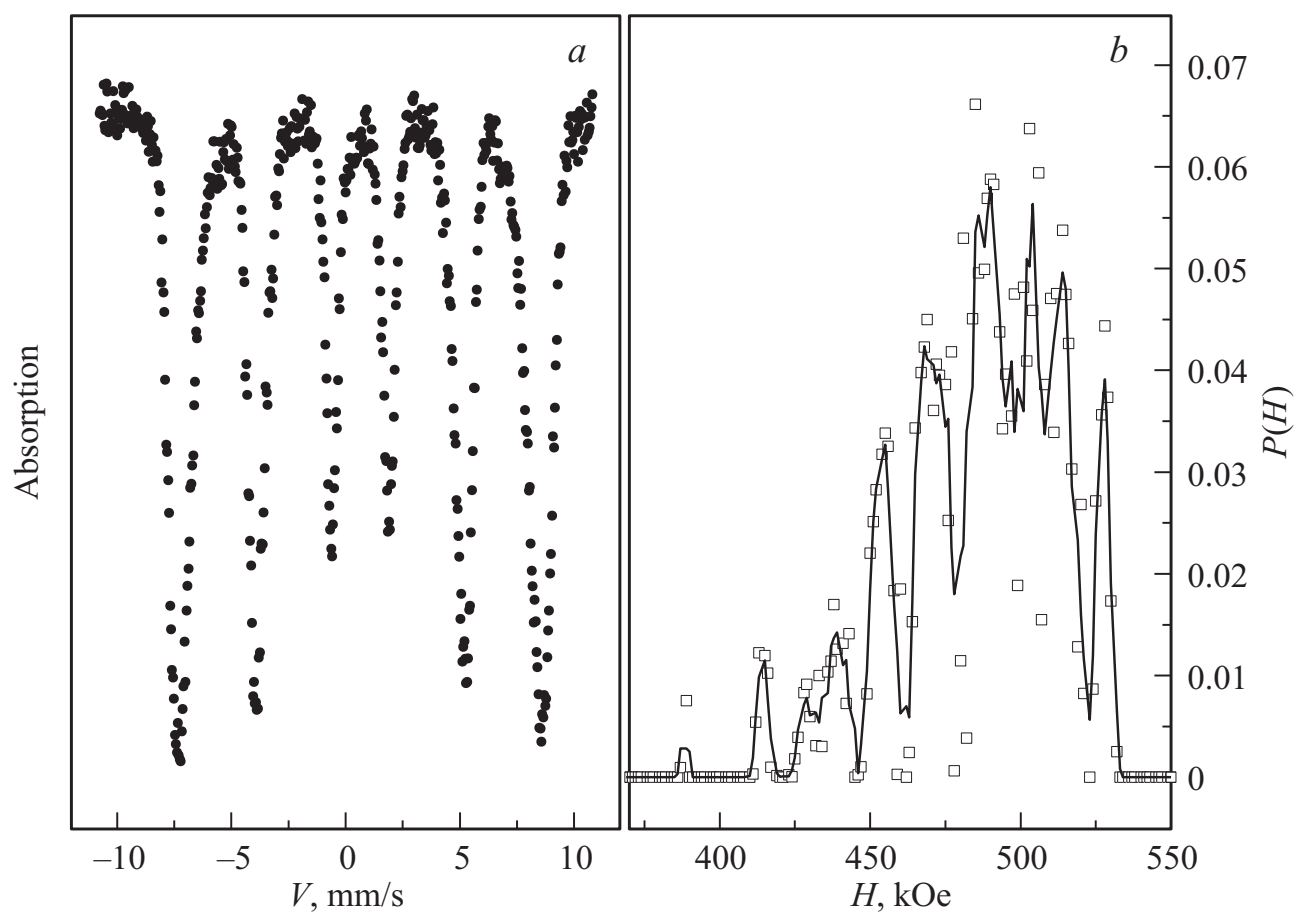

Рис. 2. Мессбауэровский спектр синтетического ферригидрита, записанный при температуре $4 \mathrm{~K}(a)$, и распределение вероятности сверхтонких полей в экспериментальном спектре $(b)$.
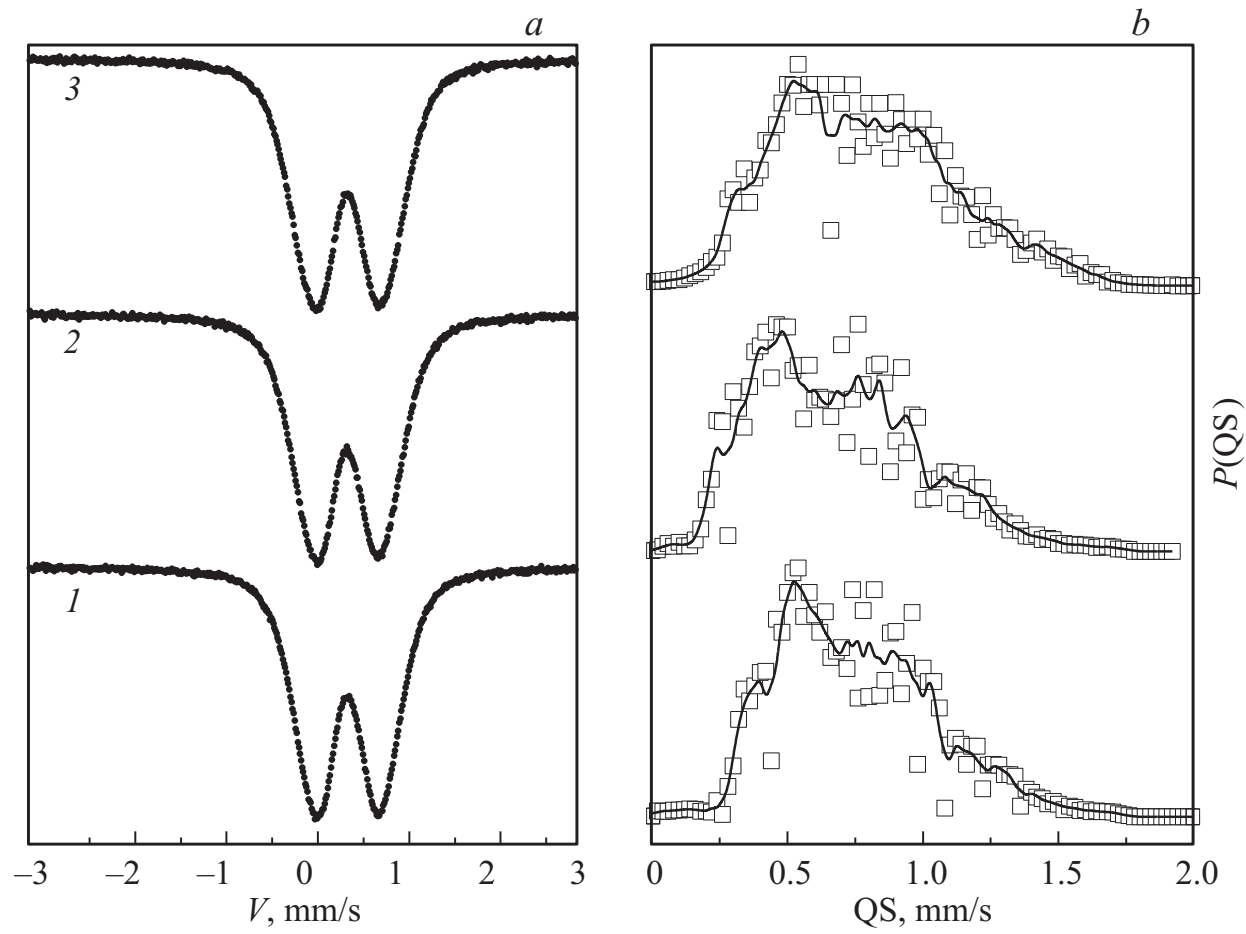

Рис. 3. Мессбауэровские спектры трех „химических“ ферригидритов $(a)$ и распределение вероятности квадрупольных расщеплений в экспериментальных спектрах $(b)$. Номера спектров соответствуют номерам образцов в табл. 3.

Расшифровка спектра проведена в два этапа. На первом этапе определено распределение сверхтонких полей $P(H)$ в экспериментальном спектре. Далее по положениям максимумов оценивались число и параметры неэкви- валентных позиций ионов железа и строился модельный спектр. Модельный спектр подгонялся к экспериментальному при варьировании всего набора сверхтонких параметров. Такая подгонка приводила к обращению 


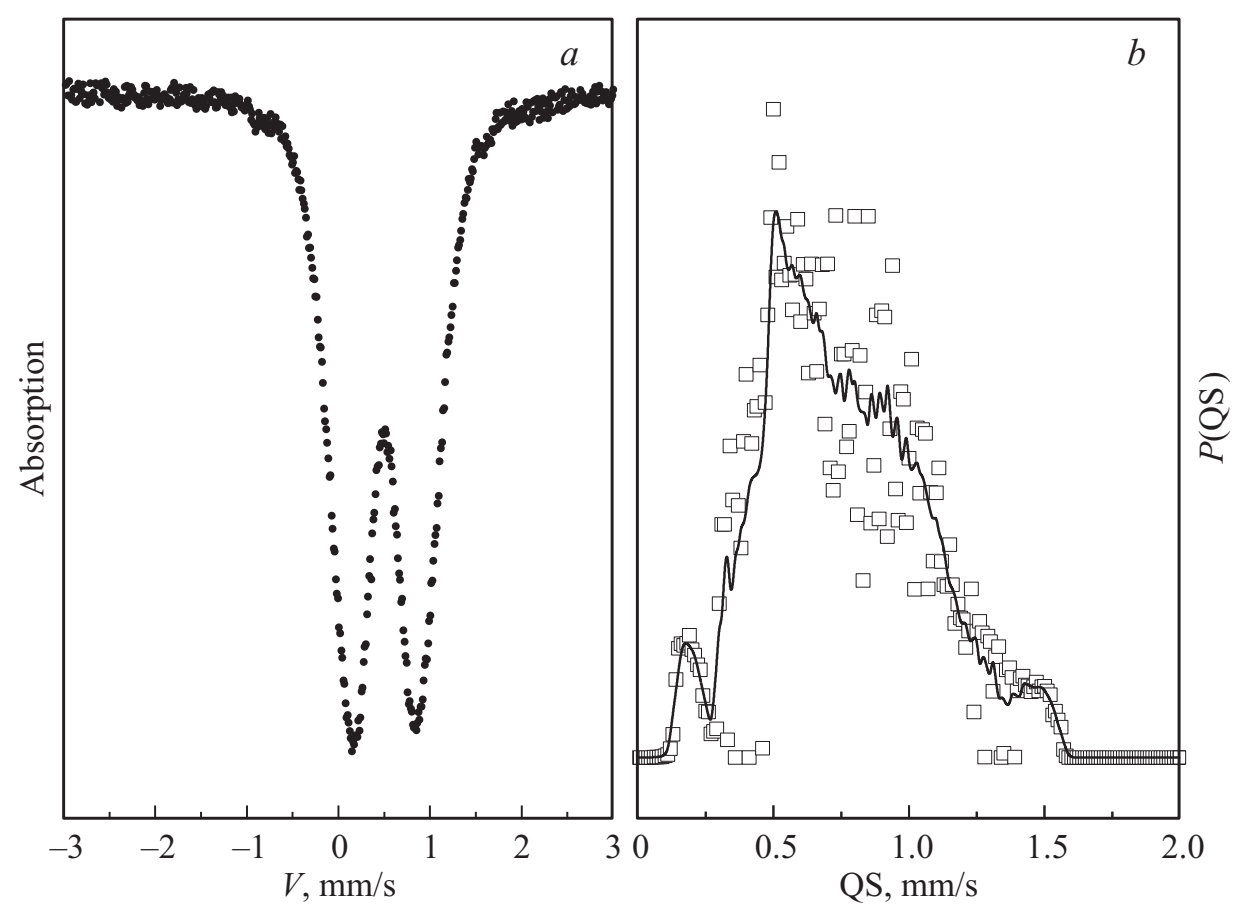

Рис. 4. Мессбауэровский спектр ферригидрита, легированного кобальтом $(a)$, и распределение вероятности квадрупольных расщеплений в экспериментальном спектре $(b)$.

в нуль ложных составляющих спектра и уточнению параметров реальных подспектров. В табл. 2 приведены параметры парциальных секстетов, полученные в результате такой расшифровки. Рассчитанные параметры, в частности величины сверхтонких полей $H$, заселенности обнаруженных позиций $A$, величины квадрупольного расщепления QS, удовлетворительно согласуются с параметрами спектров Мессбауэра, полученных на ферригидритах природного и искусственного происхождения [2]. Заметное различие изомерных сдвигов в двух экспериментах может быть связано с разным числом ОН-групп в окружении ионов $\mathrm{Fe}^{3+}$, что существенно влияет на электронную плотность на ядре железа [4].

На рис. 3 представлены мессбауэровские спектры, измеренные при комнатной температуре для трех образцов синтетического ферригидрита, полученных при различных скоростях добавления щелочи $\mathrm{NaOH}$. Спектры представляют собой квадрупольные дублеты, характерные для разблокированных суперпарамагнитных (SP) частиц, с различной степенью уширения линий. Анализ распределения квадрупольных расщеплений $P(\mathrm{QS})$ в экспериментальных спектрах (рис. 3, $b$ ) приводит к выводу о наличии по крайней мере трех неэквивалентных позиций железа с различной степенью искажения локального окружения. Модельные спектры формировались с учетом особенностей, наблюдаемых на распределении $P(\mathrm{QS})$, и подгонялись к экспериментальным спектрам при варьировании всего набора сверхтонких параметров. Результат расшифровки мессбауэровских спектров сведен в табл. 3. Позиции железа, обозначенные Fe1 и
Таблица 3. Мессбауэровские параметры „химических“ ферригидритов

\begin{tabular}{c|c|c|c|c|c}
\hline $\begin{array}{c}\text { Номер } \\
\text { образца }\end{array}$ & $\begin{array}{c}\mathrm{IS}, \\
\mathrm{mm} / \mathrm{s}\end{array}$ & $\begin{array}{c}\mathrm{QS}, \\
\mathrm{mm} / \mathrm{s}\end{array}$ & $\begin{array}{c}W, \\
\mathrm{~mm} / \mathrm{s}\end{array}$ & $A$ & Позиция \\
\hline 1 & 0.348 & 0.50 & 0.35 & 0.434 & $\mathrm{Fe} 1$ \\
& 0.351 & 0.81 & 0.33 & 0.371 & $\mathrm{Fe} 2$ \\
2 & 0.350 & 1.15 & 0.36 & 0.196 & $\mathrm{Fe} 3$ \\
& 0.344 & 0.50 & 0.37 & 0.453 & $\mathrm{Fe} 1$ \\
& 0.349 & 0.83 & 0.34 & 0.368 & $\mathrm{Fe} 2$ \\
& 0.347 & 1.19 & 0.36 & 0.179 & $\mathrm{Fe} 3$ \\
& 0.348 & 0.49 & 0.36 & 0.401 & $\mathrm{Fe} 1$ \\
& 0.352 & 0.83 & 0.35 & 0.365 & $\mathrm{Fe} 2$ \\
& 0.350 & 1.19 & 0.38 & 0.233 & $\mathrm{Fe} 3$
\end{tabular}

Таблица 4. Мессбауэровские параметры ферригидрита, легированного кобальтом

\begin{tabular}{c|c|c|c|c}
\hline $\mathrm{IS}, \mathrm{mm} / \mathrm{s}$ & $\mathrm{QS}, \mathrm{mm} / \mathrm{s}$ & $W, \mathrm{~mm} / \mathrm{s}$ & $A$ & Позиция \\
\hline 0.343 & 0.50 & 0.37 & 0.45 & $\mathrm{Fe} 1$ \\
0.350 & 0.82 & 0.33 & 0.34 & $\mathrm{Fe} 2$ \\
0.348 & 1.16 & 0.35 & 0.21 & $\mathrm{Fe} 3$ \\
0.351 & 1.48 & 0.26 & 0.04 & -
\end{tabular}

$\mathrm{Fe} 2$ отвечают кубической $(A B C A B C)$ и гексагональной $(A B A B)$ упаковке лигандов соответственно, в то время как позиция $\mathrm{Fe} 3$ соответствует межслоевым ионам железа. 

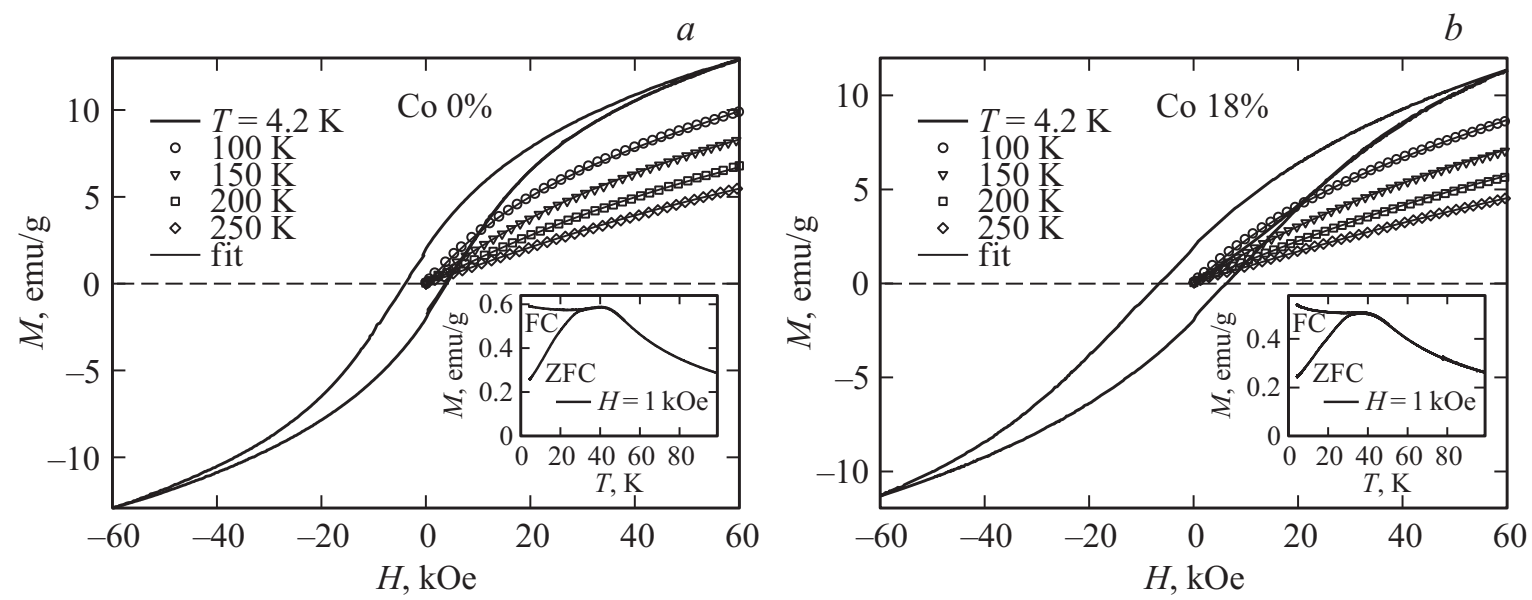

Рис. 5. Кривые намагничивания при различных температурах для наночастиц ферригидрита $(a)$ и наночастиц ферригидрита, легированного кобальтом $(b)$. Тонкие сплошные линии (fit) - результаты подгонки с помощью выражения (1). На вставках температурные зависимости магнитного момента $M(T)$, измеренные в режимах ZFC и FC.

На рис. 4 приведены спектр Мессбауэра и распределение квадрупольных расщеплений $P(\mathrm{QS})$ наночастиц, легированных кобальтом. Спектр был получен при комнатной температуре. В табл. 4 представлены результаты расшифровки. Из таблицы видно, что легирование кобальтом наночастиц оставляет параметры мессбауэровских спектров без изменений. Регистрируемые заселенности обнаруженных позиций $\mathrm{Fe} 1, \mathrm{Fe} 2, \mathrm{Fe} 3$ в легированных наночастицах идентичны заселенностям без кобальта. Полученные результаты свидетельствуют о том, что атомы кобальта равномерно распределяются среди позиций $\mathrm{Fe} 1, \mathrm{Fe} 2, \mathrm{Fe} 3$.

3.3. Результаты полученные на основе температурных и полевых зависимостей намагниченности. Температурные зависимости $M(T)$, измеренные в режимах ZFC и FC, приведенные на вставках к рис. 5, $a, b$, обнаруживают характерное $\mathrm{SP}$-поведение. Регистрируется максимум зависимости

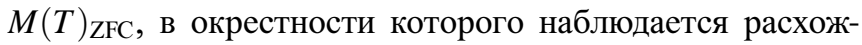
дение с зависимостью $M(T)_{\mathrm{FC}}$. При $T<T_{B}$ зависимости $M(H)$ демонстрируют гистерезис (рис. 5, $a, b)$.

Для количественного анализа зависимостей $M(H)$ при температурах $T>T_{B}$ использовался подход, общепринятый для систем невзаимодействующих АF-наночастиц, в котором магнитный момент образца обусловлен SPповедением отдельных частиц с учетом их распределения по магнитным моментам, а также составляющей $\chi_{\mathrm{AF}} H$, определяющей антиферромагнитный вклад в намагниченность. В этом случае зависимости $M(H)$ описываются следующим выражением [16-18]:

$$
M(H)=N_{P} \int^{\mu_{\max }} \mu_{\min } L\left(\mu_{P}, H\right) f\left(\mu_{P}\right) \mu_{P} d \mu_{P}+\chi_{\mathrm{AF}} H .
$$

В этом выражении $L\left(\mu_{P}, H\right)=\operatorname{coth}\left(\mu_{P} H / k T\right)$ $-1 /\left(\mu_{P} H / k T\right)$ - функция Ланжевена; $f\left(\mu_{P}\right)-$ функция распределения магнитного момента частиц $\mu_{P}$;
Таблица 5. Характеристики полученных образцов

\begin{tabular}{|c|c|c|c|c|c|}
\hline Образец & $\begin{array}{l}D, \\
\mathrm{~nm}\end{array}$ & $\begin{array}{c}T_{B}, \\
\mathrm{~K}\end{array}$ & $\begin{array}{l}H_{C}, \\
\mathrm{kOe}\end{array}$ & $\begin{array}{c}M_{S}, \\
\mathrm{G}\end{array}$ & $\begin{array}{c}\chi_{\mathrm{AF}}, 10^{-4} \\
\mathrm{emu} /(\mathrm{g} \cdot \mathrm{Oe})\end{array}$ \\
\hline $\begin{array}{l}\text { Ферригидрит } \\
\text { биологический }\end{array}$ & 2 & 23.3 & 3.6 & 26 & 0.6 \\
\hline $\begin{array}{l}\text { Ферригидрит } \\
\text { химический }\end{array}$ & 2.5 & 40 & 4 & 25 & 1.1 \\
\hline $\begin{array}{l}\text { Ферригидрит, } \\
\text { легированный Со } \\
\text { (18 at.\%) }\end{array}$ & 3.5 & 36 & 5.3 & 7 & 1 \\
\hline
\end{tabular}

$N_{P}$ - количество частиц в единице массы образца. Было использовано логнормальное распределение $f\left(\mu_{P}\right)=\left(\mu_{P} s(2 \pi)^{1 / 2}\right)^{-1} \exp \left\{-\left[\ln \left(\mu_{P} / n\right)\right]^{2} / 2 s^{2}\right\}, \quad$ где среднее значение магнитного момента частицы $\left\langle\mu_{P}\right\rangle=n \exp \left(s^{2}\right), s^{2}-$ дисперсия величины $\ln \mu_{P}$. В ходе обработки данных по выражению (1) добивались наилучшего согласия экспериментальных и подгоночных кривых [16] при каждой температуре. Из температурных зависимостей $\left\langle\mu_{P}\right\rangle(T)$ и $\chi_{\mathrm{AF}}(T)$ путем экстраполяции к $T=0 \mathrm{~K}$ определялись значения $\left\langle\mu_{P}\right\rangle(T)(T=0)$ и $\chi_{\mathrm{AF}}(T=0)$ (табл. 5).

В табл. 5 приведены величины размера $D$ частиц, температуры блокировки $T_{B}$, коэрцитивного поля $H_{C}$, намагниченности насыщения $M_{S}$ и антиферромагнитной восприимчивости $\chi_{\mathrm{AF}}$. Для сравнения в таблице также представлены характеристики наночастиц ферригидрита, полученных в результате культивирования бактерий $[4,19,20]$.

3.4. Результаты исследований методом ферромагнитного резонанса (ФМР). Температурные зависимости величины резонансных полей и ширины линии ФМР зависят от химического состава изучаемых наночастиц. На рис. 6 приведены кривые ФМР наночастиц ферригидрита. Видно, что легирование атома- 

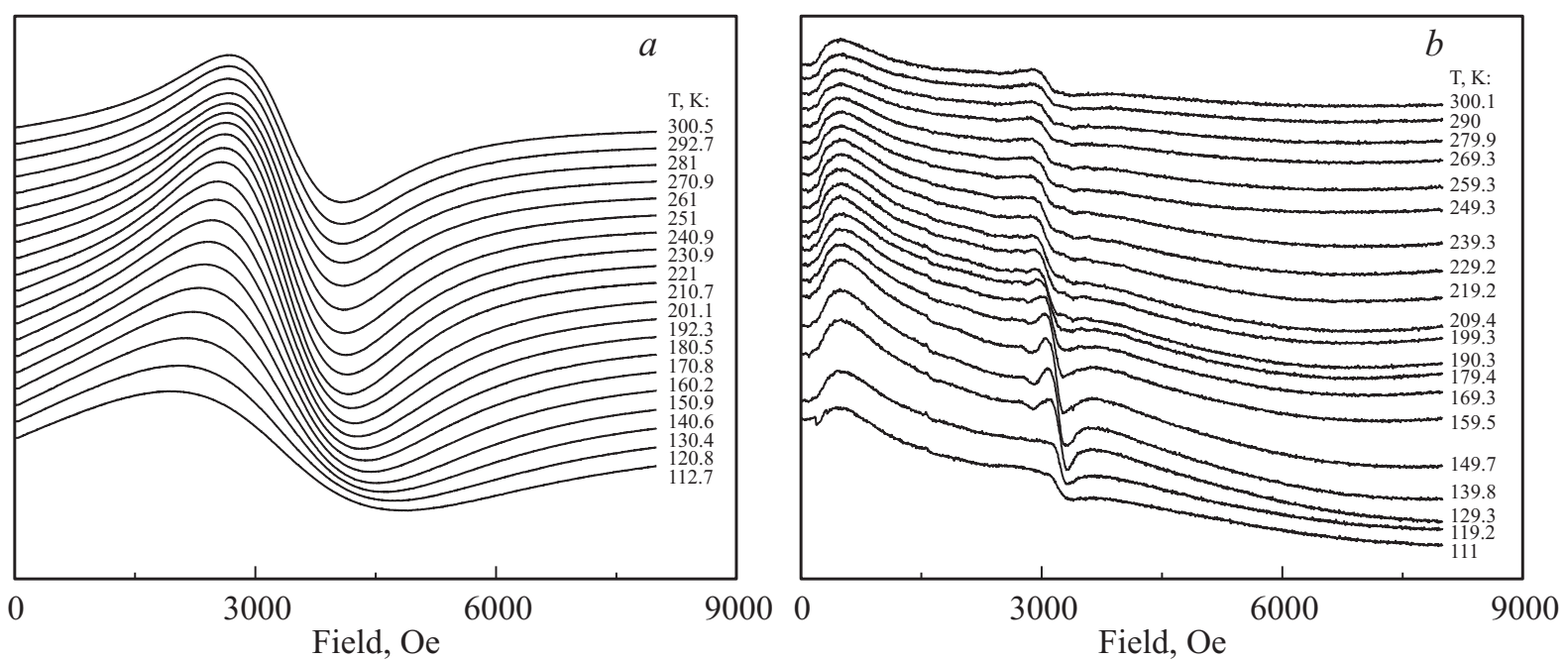

Рис. 6. Спектры ферромагнитного резонанса, записанные в диапазоне температур $\sim 100-300 \mathrm{~K}$, для наночастиц ферригидрита $(a)$ и наночастиц, легированных кобальтом $(b)$.
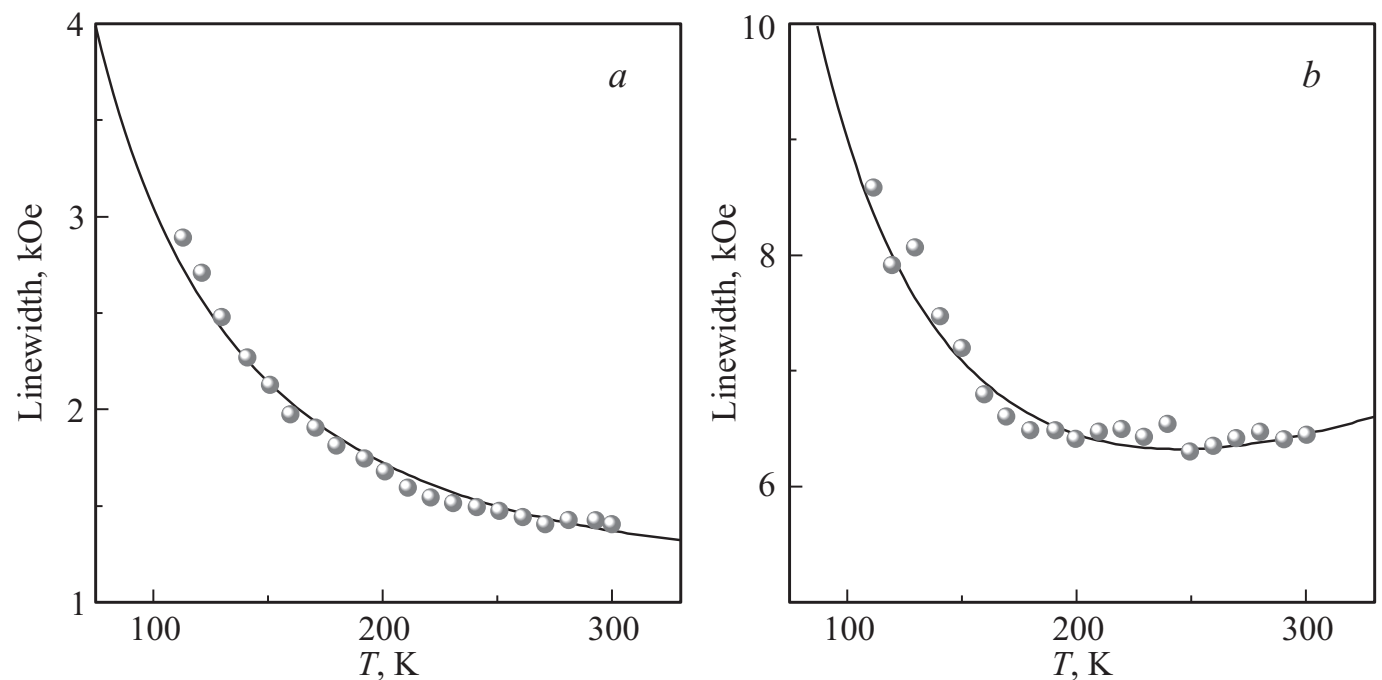

Рис. 7. Температурные зависимости ширины линии ферромагнитного резонанса для наночастиц ферригидрита $(a)$ и ферригидрита, легированного кобальтом $(b)$. Сплошные линии - результат подгонки.

ми кобальта существенно модифицирует спектры поглощения. На рис. 7 показаны температурные зависимости ширины линии ферромагнитного резонанса $\Delta H(T)$. Согласно результатам работ $[21,22]$, в порошках хаотически ориентированных частиц ферромагнетиков и ферритов ширина линии поглощения оказывается немонотонной функцией температуры: $\Delta H(T)=\Delta H_{s}(T)+\Delta H_{u}(T)$, где $\Delta H_{s}(T)$ - вклад в уширение, обусловленный суперпарамагнетизмом наночастиц, $\Delta H_{u}(T)$ - вклад в уширение, обусловленный разбросом направлений полей анизотропии частиц (неоднородное уширение), который является определяющим при низких температурах. $\Delta H_{s}(T)$ и $\Delta H_{u}(T)$ являются функциями ланжевеновского параметра $x=(M V \omega) /(\gamma k T)$, где $M-$ намагниченность, $V$ - объем частицы, $k-$ постоянная Больцмана, $T$ - температура, $\omega$ - частота, $\gamma-$ гиро- магнитное отношение. $\Delta H_{s}(T)=\omega \alpha\left(x-L_{1}\right) /\left(\sqrt{3} x \gamma L_{1}\right)$; $\Delta H_{u}(T)=\left(3 \omega \varepsilon L_{2}\right) /\left(\gamma L_{1}\right)$, где $\alpha=0.01$ - параметр затухания, $\varepsilon=K \gamma / M \omega, K-$ константа анизотропии, $L_{1,2}$ - функции Ланжевена.

Кривые, приведенные на рис. 7, характеризуются двумя подгоночными параметрами: $K V$ и $M V$. Для случая исходных наночастиц ферригидрита $K V=2 \cdot 10^{-14} \mathrm{erg}$ и $M V=2.4 \cdot 10^{-18} \mathrm{emu}$. Для наночастиц, легированных кобальтом, $K V=5.3 \cdot 10^{-14} \mathrm{erg}$ и $M V=2.46 \cdot 10^{-19}$ emu. В табл. 6 представлены полученные значения, а также приведены $K V$ и $M V$ наночастиц ферригидрита биогенного происхождения, резонансные кривые для которых были приведены в работе [20]. В таблице также приведены соответствующие параметры ферритиновых комплексов, рассчитанные из температурных кривых ФМР [23]. 
Таблица 6. Подгоночные параметры кривых, полученных при помощи теории $[21,22]$

\begin{tabular}{|c|c|c|c|c|}
\hline \multirow{2}{*}{ Параметр } & \multicolumn{3}{|c|}{ Ферригидрит } & \multirow{2}{*}{$\begin{array}{c}\text { Ферритин } \\
\text { [23] }\end{array}$} \\
\hline & биогенный & химический & химический $+\mathrm{Co}$ & \\
\hline & $1.25 \cdot 10^{-14}$ & $2 \cdot 10^{-14}$ & $5.3 \cdot 10^{-14}$ & $2.5 \cdot 10^{-14}$ \\
\hline$M V, \mathrm{emu}$ & $2.37 \cdot 10^{-18}$ & $2.4 \cdot 10^{-18}$ & $2.46 \cdot 10^{-19}$ & $1.9 \cdot 10^{-17}$ \\
\hline
\end{tabular}

Как для наночастиц ферригидрита, так и для легированных Со наночастиц в исследуемом диапазоне температур интенсивность сигнала ФМР наночастиц ферригидрита практически линейно уменьшалась во всем измеряемом диапазоне температур, что свидетельствует о том, что наночастицы находятся в разблокированном, суперпарамагнитном состоянии.

На рис. 8 приведены зависимости резонансных полей изучаемых наночастиц ферригидрита. Точки кривой 1 описывают зависимость $H_{r}(T)$ наночастиц ферригидрита, точки кривой $2-$ зависимость $H_{r}(T)$ наночастиц ферригидрита, легированных кобальтом. Резонансное поле наночастиц ферригидрита в рассматриваемом диапазоне температур остается неизменным $H_{r}=\omega / \gamma=3350$ Ое. Для наночастиц, легированных кобальтом, наблюдается немонотонный рост $H_{r}(T) \quad\left(H_{r}=1000\right.$ Ое при $T=100 \mathrm{~K}, \quad H_{r}=1600$ Ое при $T=300 \mathrm{~K}$ ), причем выполняется соотношение $H_{r}<\omega / \gamma$. Другими словами, наблюдается изотропный сдвиг $H_{r}$, зависящий от температуры, свидетельствующий о наличии в наночастицах ферригидрита, легированных кобальтом, поверхностной анизотропии вращательного типа [24]. Как известно, поверхностная магнитная анизотропия обусловлена отличием симметрии окружения поверхностных атомных магнитных моментов от имеющей место для объемных.

Одной из разновидностей поверхностной анизотропии является однонаправленная обменная анизотропия, воз-

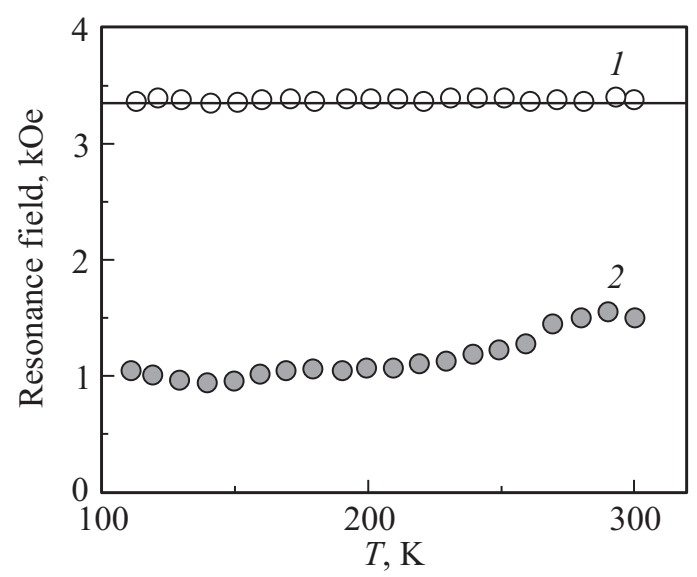

Рис. 8. Зависимость резонансного поля от температуры для наночастиц ферригидрита (1) и наночастиц легированных кобальтом (2). никающая на границе раздела ферро(ферри)магнетикантиферромагнетик $[25,26]$. Явление однонаправленной анизотропии, заключающееся в существовании единственного энергетически выгодного направления для вектора намагниченности $M$, внешне проявляется в смещении петли гистерезиса $M(H)$ относительно нулевого значения приложенного магнитного поля $H$. Однако если кристаллографическая анизотропия антиферромагнетика невелика, то смещение петли гистерезиса не наблюдается (увеличивается коэрцитивное поле), а магнитная структура антиферромагнитного слоя будет поворачиваться вслед за приложенным внешним полем. В данном случае поверхностная анизотропия будет являться вращательной анизотропией. Обнаружение однонаправленной анизотропии в антиферромагнитных наночастицах, например $\mathrm{NiO}[6,27,28]$, а также в изучаемых нами антиферромагнитных наночастицах ферригидрита может быть связано с „ферромагнитной“ поверхностью, обусловленной дефектностью, или же со спин-стекольным поведением поверхности, также обусловленной дефектами. Согласно результатам работ $[29,30], 3 K_{u} / M R=\omega / \gamma-H_{R}$, где $K_{u}$ - константа поверхностной анизотропии, $M-$ намагниченность, $R$ - радиус частицы. Подставляя в данное выражение величины $M$ и $R$, найденные при фитировании зависимостей $\Delta H(T)$, получаем константу вращательной анизотропии $K_{u}=1.6 \cdot 10^{-3} \mathrm{erg} / \mathrm{cm}^{2}$.

\section{4. Заключение}

Методом гидролиза солей железа получены порошки наночастиц ферригидрита и наночастиц ферригидрита, легированных кобальтом. Определены размеры частиц, величины намагниченности, константы поверхностной и объемной анизотропии, температуры блокировки. Легирование кобальтом приводит к существенному увеличению константы анизотропии частицы и формированию поверхностной вращательной анизотропии с $K_{u}=1.6 \cdot 10^{-3} \mathrm{erg} / \mathrm{cm}^{2}$.

\section{Список литературы}

[1] A.-H. Lu, E.L. Salabas, F. Schüth. Angew. Chem. Int. Ed. 46, 1222 (2007).

[2] E. Murad, U. Schwertmann. Am. Mineral. 65, 1044 (1980).

[3] E. Jansen, A. Kyek, W. Schafer, U. Schwertmann. Appl. Phys. A 74, s1004 (2002).

[4] S.V. Stolyar, O.A. Bayukov, Y.L. Gurevich, V.P. Ladygina, R.S. Iskhakov, P.P. Pustoshilov. Inorg. Mater. 43, 638 (2007).

[5] Z. Wang, C. Li, M. Ellenburg, E. Soistman, J. Ruble, B. Wright, J.X. Ho, D.C. Carter. Acta Cryst. D 62, 800 (2006).

[6] S.A. Makhlouf, F.T. Parker, F.E. Spada, A.E. Berkowitz. J. Appl. Phys. 81, 5561 (1997).

[7] J.T. Richardson, D.I. Yiagas, B. Turk, K. Forster, M.V. Twigg. J. Appl. Phys. 70, 6977 (1991).

[8] R.D. Zysler, D. Fiorani, A.M. Testa, L. Suber, E. Agostinelli, M. Godinho. Phys. Rev. B 68, 212408 (2003). 
[9] X.G. Zheng, C.N. Xu, K. Nishikubo, K. Nishiyama, W. Higemoto, W.J. Moon, E. Tanaka, E.S. Otabe. Phys. Rev. B 72, 014464 (2005).

[10] K. Dobretsov, S. Stolyar, A. Lopatin. Acta Otorhinolaryngol. Ital. 35, 97 (2015).

[11] E.V. Inzhevatkin, E.V. Morozov, E.D. Khilazheva, V.P. Ladygina, S.V. Stolyar, O.V. Falaleev. Bull. Exp. Biol. Med. 158, 807 (2015).

[12] A. Punnoose, T. Phanthavady, M.S. Seehra, N. Shah, G.P. Huffman. Phys. Rev. B 69, 054425 (2004).

[13] Д.А. Балаев, Ю.В. Бояршинов, М.М. Карпенко, Б.П. Хрусталев. ПТЭ 3, 167 (1985).

[14] R.K. Kukkadapu, J.M. Zachara, J.K. Fredrickson, S.C. Smith, A. C. Dohnalkova, C. K. Russell. Am. Mineral. 88, 1903 (2003).

[15] Y. Guyodo, S.K. Banerjee, R. Lee Penn, D. Burleson, T.S. Berquo, T. Seda, P. Solheid. Phys. Earth Planet. Inter. 154, 222 (2006).

[16] D.A. Balaev, A.A. Krasikov, A.A. Dubrovskiy, S.I. Popkov, S.V. Stolyar, O.A. Bayukov, R.S. Iskhakov, V.P. Ladygina, R. N. Yaroslavtsev. J. Magn. Magn. Mater. 410, 171 (2016).

[17] N.J.O. Silva, V.S. Amaral, L.D. Carlos. Phys. Rev. B 71, 184408 (2005).

[18] C. Gilles, P. Bonville, H. Rakoto, J.M. Broto, K.K.W. Wong, S. Mann. J. Magn. Magn. Mater. 241, 430 (2002).

[19] Д.А. Балаев, А.А. Красиков, А.А Дубровский, С.В. Семенов, О.А. Баюков, С.В. Столяр, Р.С. Исхаков, В.П. Ладыгина, Л.А. Ищенко. ЖЭТФ 146, 546 (2014).

[20] Д.А. Балаев, А.А. Красиков, С.В. Столяр, Р.С. Исхаков, В.П. Ладыгина, Р.Н. Ярославцев О.А. Баюков, А.М. Воротынов, М.Н. Волочаев, А.А. Дубровский. ФТТ 58, 1724 (2016).

[21] Ю.Л. Райхер, В.И. Степанов. ЖЭТФ 102, 1409 (1992).

[22] I.S. Poperechny, Y.L. Raikher. Phys. Rev. B 93, 014441 (2016).

[23] E. Wajnberg, L.J. El-Jaick, M.P. Linhares, D.M.S. Esquivel. J. Magn. Res. 153, 69 (2001).

[24] R.J. Prosen, J.O. Holmen, B.E. Gran. J. Appl. Phys. 32, S91 (1961).

[25] J. Nogués, I.K. Schuller. J. Magn. Magn. Mater. 192, 203 (1999).

[26] W.H. Meiklejohn, C.P. Bean. Phys. Rev. 102, 1413 (1956).

[27] S.A. Makhlouf, H. Al-Attar, R.H. Kodama. Solid State Commun. 145, 1 (2008).

[28] H. Bi, S. Li, Y. Zhang, Y. Du. J. Magn. Magn. Mater. 277, 363 (2004).

[29] F. Gazeau, J.C. Bacri, F. Gendron, R. Perzynski, Yu.L. Raikher, V.I. Stepanov, E. Dubois. J. Magn. Magn. Mater. 186, 175 (1998).

[30] F. Gazeau, V. Shilov, J.C. Bacri, E. Dubois, F. Gendron, R. Perzynski, Y.L. Raikher, V.I. Stepanov. J. Magn. Magn. Mater. 202, 535 (1999). 